\author{
PRÉMIO PROF. DOUTOR \\ JOAQUIM CERQUEIRA GONÇALVES (2013)
}

\title{
A Ética dos Deveres Prima Facie, DE DAVID ROSS, SERÁ UMA FORMA CREDÍVEL DE DEONTOLOGIA?
}

Miguel Rebelo

(Departamento de Filosofia, Universidade de Lisboa)

\section{Introdução}

São sobejamente conhecidos os problemas de uma perspectiva deontológica que admita restrições absolutas à promoção do bem. No entanto, William David Ross conseguiu produzir uma versão "moderada" que escapa às objecções tradicionais apontadas a uma concepção deontológica absolutista. Porém, tentarei ao longo do presente texto demonstrar que uma ética de deveres prima facie apresenta debilidades derivadas dos seus fundamentos epistémicos.

\section{Uma ética de deveres prima facie}

A originalidade da perspectiva deontológica apresentada por W.D. Ross é animada pelo desejo de aproximar a ética ao modo de decisão intuitivo a qualquer agente sem treino filosófico quando colocado perante dilemas morais. Ross procura captar a forma como cada um de nós se comporta moralmente perante os demais nas diversas relações que desempenhamos, de pai para filho, de amigo para amigo, de conterrâneo para conterrâneo, etc., algo que o utilitarismo é incapaz de preservar por reduzir a posição que tomamos uns ante os outros, no plano moral, à de beneficiários da acção alheia. Não será objectivo do presente trabalho discutir a resposta rossiana ao utilitarismo. No entanto, este ponto de partida é importante por revelar a sensibilidade de Ross à adequação da ética às convicções morais mais comuns, rejeitando uma perspectiva de ética normativa que, em suas palavras, se preocupe em apresentar uma

Philosophica, 42, Lisboa, 2013, pp. 183-188. 
"simetria arquitectónica ou simplicidade apressadamente alcançada" sem salvaguardar a "lealdade aos factos". 1

Ora, ao enfrentarmos um dilema moral, habitualmente equilibramos os vários factores relevantes, dadas as circunstâncias, e, considerando o modo como interagem, tomamos uma decisão. A este jogo de articulação entre factores moralmente relevantes correspondem os deveres prima facie, que Ross apresenta como deveres contributivos para a realização ou não de determinadas acções. Não representam deveres absolutos, mas sim deveres tendenciais. Ou seja, o facto de um certo acto apresentar uma propriedade $p$ é tendencialmente uma razão para o (não) realizar. A lista de deveres prima facie sugerida por Ross contempla deveres de fidelidade (ex. cumprimento de promessas), de reparação (por um mal anteriormente realizado), de gratidão (por um bem previamente recebido), de justiça, de beneficência (ex. ajuda a terceiros ao nosso alcance), de desenvolvimento pessoal e de não-maleficência (isto é, de não infligir um mal a outrem). Mas ressalve-se que esta lista não procura ser completa e pode inclusive ser alvo de alterações. Não se trata de um conjunto coerente e hierarquicamente estruturado, pois o processo de determinação de qual o dever prima facie de maior força só pode ser verificado no processo de deliberação do agente perante um dilema moral concreto. Assim, entramos na epistemologia moral rossiana, que equipara o conhecimento dos deveres prima facie ao conhecimento das leis matemáticas, na medida em que são deveres auto-evidentes após reflexão por qualquer "agente suficientemente amadurecido". 2

\section{A epistemologia moral rossiana}

Ross sugere que o conhecimento da verdade de um princípio se concretiza através da experiência moral. Podemos estabelecer três momentos da sua epistemologia moral: num primeiro momento o agente discrimina a propriedade relevante auto-evidente que favoreça prima facie a concretização de um acto em circunstâncias particulares; num

\footnotetext{
1 "Loyalty to the facts is worth more than a symmetrical architectonic or a hastily reached simplicity." (W. D. Ross, "What Makes Right Acts Right?" in Ethical Theory, Russ Shafer-Landau (ed.), Oxford: Blackwell Publishers, 2007, p. 755).

2 "That an act [...] is prima facie right is self-evident; [...] It is self-evident just as a mathematical axiom, or the validity of a form of inference, is evident. [...] In a precisely similar way, we see the prima facie rightness of an act which would be the fulfillment of a particular promise, and when we have reached sufficient maturity to think in general terms, we apprehend prima facie rightness to belong to the nature of any fulfillment of promise." (ibid. p. 756).
} 
segundo momento reconhece qual o princípio geral que constitui o dever prima facie, a partir da discriminação da propriedade relevante do acto em causa realizada no primeiro momento; por fim, na determinação de qual o dever efectivo, dadas as circunstâncias, considera o dever prima facie que contribua para a realização do acto, assim como outros deveres prima facie que contribuam ou não para a sua realização, caso esse mesmo acto apresente outras propriedades moralmente relevantes.

O conhecimento da propriedade relevante e a apreensão do respectivo princípio geral são auto-evidentes. Já a deliberação sobre o dever efectivo não poderá sair das águas turvas de uma opinião provável. Ross, com efeito, não admite uma hierarquia clara entre os vários deveres prima facie, cabendo ao agente equacioná-los no seio da conjuntura particular com que depare. Para uma mais clara compreensão do que isto significa, tomemos em atenção o seguinte exemplo:

Marco recebe um telefonema do seu amigo Alexandre, que lhe pergunta se estaria disponível para passar pela sua nova casa no Restelo para ajudá-lo a montar uma luxuosa estante em chapa de carvalho recém-chegada do IKEA. De temperamento prestimoso, Marco aceita e combina encontrar-se com Alexandre em sua casa às 15 horas desse dia. Aproximando-se a hora acordada, Marco põe-se a caminho. No preciso momento em que está prestes a chegar à paragem de autocarro, recebe um novo telefonema. Desta vez é a sua colega Luísa, que em tom de aflição lhe diz que está detida na esquadra do Calvário por atitudes desordeiras durante o almoço de turma, e roga-lhe para que a liberte sob fiança $o$ quanto antes, de modo a conseguir apanhar o comboio das 15 horas e 45 minutos em Sta. Apolónia com destino a Bragança, o último do dia devido a greve da $\mathrm{CP}$, e poder chegar a horas do jantar anual de família, que contará com a presença inédita de seu pai, refugiado político em Cuba que a filha nunca chegara a conhecer e que ficará por terra lusas apenas naquela noite. Note-se que Luísa, rapariga introvertida e tímida de uma aldeia remota do norte do país, poucas amizades fez em Lisboa, sendo Marco a única pessoa com quem pode contar para se livrar desta alhada. Marco tenta contactar Alexandre de modo a adiar o prometido, mas infrutiferamente. Não há qualquer possibilidade de cumprir com os pedidos de ambos.

Perante este dilema, de que forma deverá agir? Seguindo os meandros do processo rossiano, Marco terá de reconhecer, em primeiro lugar, as propriedades relevantes em questão, que poderemos reduzir ao cumprimento com o prometido a Alexandre, à importância de auxiliar a sua colega Luísa e, porventura, à justeza do recurso ao dinheiro como expediente para reparar a desordem por ela provocada no almoço de turma. De seguida, a partir das propriedades consideradas ser-nos-á possível apreender, respectivamente, deveres de fidelidade, de beneficên- 
cia e de justiça. Se nos restringirmos às consequências de cada acto, verificaremos que certamente será mais valioso ajudar Luísa. Afinal de contas, que importância terá uma estante? Provavelmente será um ligeiro incómodo para Alexandre não a ver de pé naquele dia, mas como compará-lo à perda da primeira (e talvez última) oportunidade que Luísa terá para encontrar o pai que nunca conheceu? Segundo uma perspectiva consequencialista, a situação não parece impor quaisquer problemas significativos à decisão a tomar. No entanto, obedecendo à cartilha rossiana, estamos perante três deveres prima facie conflituantes que contribuem decisivamente para a realização de qualquer escolha de Marco. Resta-lhe ter a clarividência suficiente para decidir qual "o dever que, dadas as circunstâncias, será mais dever" ${ }^{3}$ e agir segundo a conclusão a que chegar. ${ }^{4}$

Um princípio moral, para ser considerado como tal, deverá ser aplicável do mesmo modo em quaisquer circunstâncias. Portanto, se, por exemplo, o cumprimento de uma promessa for aceite como favoravelmente contributivo para a realização de um acto nas circunstâncias $\mathrm{C}$, sê-lo-á em todas e quaisquer circunstâncias sem excepção. Se não admitirmos isto, então concordamos com a verdade de ambas as seguintes premissas, o que constitui uma contradição:

(1) O cumprimento de uma promessa é um dever prima facie contributivo para a realização do acto $\mathrm{X}$.

(2) Não é o caso que o cumprimento de uma promessa seja um dever prima facie contributivo para a realização do acto $\mathrm{X}$.

No processo de conhecimento moral rossiano, o reconhecimento das propriedades moralmente relevantes de um acto é fruto da reflexão conducente à aceitação intuitiva da sua auto-evidência. Mas dificilmente se alegará que a humanidade concorde em uníssono no que toca a intuições éticas, pois se fosse esse o caso não se verificaria qualquer conflito ético. Assim, se aceitarmos o conflito de intuições, então aceitaremos também a

\footnotetext{
3 "It may be said that besides the duty of fulfilling promises I have and recognize a duty of relieving distress, and that when I think it right to do the latter at the cost of not doing the former, it is not because I think I shall produce more good thereby but because I think it the duty which is in the circumstances more of a duty." (ibid. p. 753).

4 "When I am in a situation, as perhaps I always am, in which more than one of these prima facie duties is incumbent on me, what I have to do is to study the situation as fully as I can until I form the considered opinion (it is never more) that in the circumstances one of them is more incumbent than any other; then I am bound to think that to do this prima facie duty is my duty sans phrase in the situation." (ibid. p. 754).
} 
possibilidade de um mesmo dever prima facie, derivado da propriedade relevante auto-evidente de um acto, se apresentar em simultâneo como contributivo para a realização e para a não realização de um acto, ao sabor das intuições morais de cada agente. Ou aceitamos o relativismo moral ou assumimos a possibilidade de contradição que um princípio geral assente em intuições acarreta. Em ambos os casos, não é possível alcançar conhecimento objectivo da verdade moral.

E porém, Ross fala numa reflexão realizada por um agente "suficientemente amadurecido". Coloca-se-lhe a seguinte questão: a propriedade $x$ de um acto é favorável à sua concretização por ser auto-evidente a um agente suficientemente amadurecido, ou um agente é suficientemente amadurecido por lhe ser auto-evidente que a propriedade $x$ de um acto é favorável à sua concretização? O já velhinho dilema de Êutifron aplica-se como segunda objecção à epistemologia moral rossiana. Pois se a propriedade $x$ de um acto é favorável à sua concretização por ser auto-evidente a um agente suficientemente amadurecido, caímos no subjectivismo moral do agente que apresente um certo grupo de características que constituam no seu conjunto condição suficiente para que possa ser considerado um agente amadurecido, seja lá o que isso for. Se, por outro lado, um agente é suficientemente amadurecido por lhe ser auto-evidente que a propriedade $x$ de um acto é favorável à sua concretização, então cai por terra o processo epistémico fundado na experiência moral, pois neste caso o que determina se um agente é amadurecido é o facto de considerar auto-evidente a relevância de uma determinada propriedade, que deverá estar previamente estabelecida como tal, o que, como vimos, contraria a proposta rossiana, que defende que a apreensão de qual a propriedade relevante de um acto para que a sua realização seja favorável é um corolário da experiência directa do agente com uma situação particular de dilema moral.

\section{Conclusão}

No projecto de fazer coincidir a ética com o modo como habitualmente a pensamos em situações quotidianas, Ross falha em apresentar uma perspectiva deontológica que satisfaça a exigência de conhecimento objectivo da verdade moral, precisamente por tentar fundamentar a sua epistemologia moral numa tese intuicionista. Se este modo de deontologia é à primeira vista mais atraente que a sua contraparte absolutista, falha por não avançar bases epistémicas sólidas que a sustentem. 


\title{
Bibliografia
}

DANCY, Jonathan, "An ethic of prima facie duties", in A Companion to Ethics, Peter Singer (ed.), Oxford: Blackwell Publishers, 1996.

ROSS, W.D., "What Makes Right Acts Right?" in Ethical Theory, Russ Shafer-Landau (ed.), Oxford: Blackwell Publishers, 2007.

SKELTON, Anthony, "William David Ross", in The Stanford Encyclopedia of Philosophy (Summer 2012 Edition), Edward N. Zalta (ed.).

\section{RESUMO}

O contributo dado por W.D. Ross à ética normativa é um notável esforço de aproximação da ética, como disciplina filosófica, às intuições pré-filosóficas que quotidianamente orientam os processos de decisão de qualquer agente moral comum. Ross alcança este resultado ao assumir bases epistémicas de carácter intuicionista na construção do edifício da sua deontologia dos deveres prima facie. Ainda que o respeito pelas intuições éticas mais comuns possa parecer vantajoso como ponto de partida para a teoria ética, procuro demonstrar no presente ensaio que as principais fragilidades da deontologia rossiana encontram-se precisamente nos princípios epistémicos que lhe servem de fundamento.

Palavras-chave: deveres; intuições; deontologia; epistemologia moral.

\begin{abstract}
W.D. Ross's contribution to normative ethics is a remarkable attempt to bring together ethics, understood as a philosophical discipline, and the pre-philosophical intuitions which guide the daily decision processes of the average moral agent. Ross achieves this result by assuming intuitionist epistemic foundations as the building blocks of his prima facie duties deontology. Even though such a consideration for the most common ethical intuitions may seem an advantage as a starting point for ethical theory, I attempt to demonstrate in this paper that the main flaws of Ross's deontology are present precisely in the epistemic principles which serve as its foundation.
\end{abstract}

Keywords: duties; intuitions; deontology; moral epistemology. 